Volume 5

\title{
The Effects of Perspective Taking Implementing Intentions on Employee Evaluations and Hostile Sexism
}

\author{
Saaid A. Mendoza \\ Providence College \\ Jeanine L. M. Skorinko \\ Worcester Polytechnic Institute \\ Sarah A. Martin \\ Worcester Polytechnic Institute \\ Lauren E. Martone \\ Providence College
}

Follow this and additional works at: https://scholarworks.bgsu.edu/pad

Part of the Human Resources Management Commons, Industrial and Organizational Psychology Commons, Organizational Behavior and Theory Commons, and the Social Psychology Commons How does access to this work benefit you? Let us know!

\section{Recommended Citation}

Mendoza, Saaid A.; Skorinko, Jeanine L. M.; Martin, Sarah A.; and Martone, Lauren E. (2019) "The Effects of Perspective Taking Implementing Intentions on Employee Evaluations and Hostile Sexism," Personnel Assessment and Decisions: Number 5 : Iss. 2 , Article 7.

DOI: https://doi.org/10.25035/pad.2019.02.007

Available at: https://scholarworks.bgsu.edu/pad/vol5/iss2/7

This Main Article is brought to you for free and open access by the Journals at ScholarWorks@BGSU. It has been accepted for inclusion in Personnel Assessment and Decisions by an authorized editor of ScholarWorks@BGSU. 


\title{
The Effects of Perspective-Taking IMPLEMENTING INTENTIONS ON EMPLOYEE Evaluations and Hostile Sexism
}

\author{
Saaid A. Mendoza', Jeanine L. M. Skorinko², Sarah A. Martin², \\ and Lauren E. Martone ${ }^{1}$
}

1. Providence College

2. Worcester Polytechnic Institute

ABSTRACT

\section{KEYWORDS}

Implementation intentions, perspective taking, gender work bias, hostile sexism, goal pursuit

\begin{abstract}
The current research examined whether gender bias in the workplace could be reduced through perspective taking implementation intentions, which are if-then statements that specify how to accomplish goals (Gollwitzer, 1999). Amazon MTurk participants (N $=180,53 \%$ male) learned they would complete a two-step performance review for a consulting company. Prior to receiving a male or female employee's record, all participants were given a goal strategy to be fair in their review, with half also receiving an if-then strategy that encouraged perspective taking. Participants rated the employee on three work related dimensions (skillset, performance, and traits), provided an overall promotion recommendation, and completed the Ambivalent Sexism Inventory (Glick \& Fiske, 1996). Although we did not find evidence of gender bias on the work measures, we found that the implementation intention strategy resulted in more positive employee evaluations overall and less hostile sexism than a simple goal strategy. We discuss the potential organizational benefits of employing perspective taking implementation intentions.
\end{abstract}

In the United States, women earn more undergraduate $(57 \%)$, master's (59\%), and doctorate $(53 \%)$ degrees than men (Catalyst, 2018). Despite these differences in educational attainment and earning potential, women still receive unequal levels of income and advancement opportunities (Valian, 2000). On average, women earn $\$ 0.80$ to every $\$ 1$ earned by men and are promoted at a lower rate than their male counterparts, especially in upper management positions (Catalyst, 2017). For instance, a recent study conducted by McKinsey \& Company (2018) in partnership with Leanin.org revealed that women make up only $38 \%$ of managers and represent approximately $1 / 5$ th of $\mathrm{C}$-suite executives. Furthermore, women currently hold merely $5 \%$ of Fortune 500 CEO roles, despite consulting advice that women can increase business profitability for corporations (McKinsey \& Company, 2016). Given these workplace gender disparities, the present research investigates strategies that may decrease biased evaluations of employee performance, especially women.

\section{Gender Bias in the Workplace}

Extant psychological theories on gender bias primarily attribute its sociocultural persistence to prescriptive norms that dictate how men and women should be. Specifically, men are stereotypically ascribed agentic (e.g., competent, assertive) traits, whereas women are expected to possess communal (e.g., warm, caring) qualities (Eagly, 1987; Fiske, Cuddy, Glick, \& Xu, 2002). In turn, this impacts the social roles that are deemed appropriate for members of each gender group, with men seen as better suited than women for high status positions in which agentic traits are expected and desired (Eagly \& Karau, 2002; Eagly \& Wood, 1991). Thus, when women pursue male-typed professions, there is often a perceived "lack of fit" due to the incongruence between their gender stereotypes and occupational requirements (Heilman, 2012).

Unsurprisingly, a substantial amount of experimental evidence has been found that women are subject to biased evaluations in male-dominated work settings (for a meta-analysis, see Koch, D'Mello, \& Sackett, 2014). For instance, research demonstrates that the standards applied to women during evaluation are different, or shift, from

\footnotetext{
Corresponding author:

Saaid A. Mendoza

Department of Psychology, Providence College

1 Cunningham Square, 0123 Sowa Hall, Providence, RI 02918

Email:smendoza@providence.edu
} 
the standards applied to men-even when the credentials are the same (Biernat \& Manis, 1994). Because women are judged by a stricter standard of competency than men in these professions, they must work harder to establish their credentials and be seen as viable job candidates (Foschi, 1996). To accomplish this, they may display more agentic behaviors that allow them to advance in the workplace. However, this comes at a significant interpersonal cost, as successful women are typically assumed to lack feminine traits and subsequently derogated for their perceived gender norm violation (Heilman \& Okimoto, 2007; Heilman, Wallen, Fuchs, \& Tamkins, 2004; Rudman \& Glick, 1999, 2001). Women therefore face a "double bind" that puts them at a significant disadvantage: first, they must overcome negative expectations of their competence, and second, they have to be careful about coming across as too masculine and unlikable. All the while, the standards by which they are being evaluated can be shifting.

These types of biases are evident in the business world, such as within the segment of consulting. Female consultants typically earn less than male consultants, account for less of the overall workforce, and are considerably underrepresented in management positions (Bain \& Company, 2018; Bhattacharyya, \& Sachin, 2016; Tomenendal \& Boyoglu, 2014). For instance, in one major consulting firm, women account for $36 \%$ of the entire workforce and represent only $31 \%$ of the executives (Bellstrom, 2016). Based on these disparities and prior gender bias research, we expect that men are likely to receive more favorable work evaluations than women in male-typed fields like consulting (Hypothesis 1). As such, we investigate strategies that can be used by an evaluator to attenuate bias in work settings.

\section{Perspective Taking}

One strategy that may be helpful for an evaluator is to take the employee's perspective during the review process. Perspective taking is the cognitive act of putting oneself in another person's shoes. Prior work in this area provides mixed results regarding its effect on intergroup bias. For example, some studies find that perspective taking can decrease egocentric tendencies (Caruso, Epley, \& Bazerman, 2006), as well as reduce stereotyping and prejudice (Galinsky \& Moskowitz, 2000; Vescio, Sechrist, \& Paolucci, 2003). These benefits are theorized to be the result of a heightened sense of similarity between the perspective taker and the target (Davis, Conklin, Smith, \& Luce, 1996; Laurent \& Myers, 2011; Myers \& Hodges, 2012).

However, other research suggests that perspective taking may not always lead to a reduction of intergroup bias, such as when the individual is dissimilar to the target, strongly identifies with the ingroup, or is unable to see the other side of a conflict (Ames, 2004a, 2004b; Frantz \& Janoff-Bulman, 2000; Tarrant, Calitri, \& Weston, 2012). Likewise, perspective taking can increase egocentric biases and enable the perspective taker to use available stereotypes when the target confirms negative outgroup expectations (Epley, Keysar, van Boven, \& Gilovich, 2004; Skorinko \& Sinclair, 2013).

Given that the positive effects of perspective taking appear to be contextually dependent, we control for some of these situational factors to reduce gender bias in our study. Specifically, we use a female target that does not confirm negative stereotypes of her group and present this employee in a noncompetitive context in relation to the evaluator. Furthermore, because perspective taking can be a challenging endeavor that requires time, motivation, and cognitive resources (Eply et al., 2004), we examine whether the process can be facilitated through the use of strategies that automatically engage goal pursuit.

\section{Goal Pursuit and Implementation Intention Effects}

Despite their best intentions, people often have a difficult time getting started on or following through with their goals, such as trying to eat healthier. Gollwitzer (1993, 1999) suggested that this is because goal intentions only state what people want to accomplish, but fail to specify where, when, and how the person must act in order for the goal to be achieved. To help translate goals into action, he proposed supplementing simple goals with implementation intentions, which are if-then statements that identify the specifics needed for successful goal attainment. For instance, an individual may form a simple goal intention ("I will eat less sweets!") and then adopt an implementation intention plan on how to accomplish it ("If I find myself craving sweets, then I will eat a piece of fruit instead of candy!").

The if and then components of an implementation intention serve separate but complementary functions in aiding goal pursuit. The if component identifies a goal-relevant situational cue that can be anticipated (e.g., craving sweets), whereas the then component provides the action that should be initiated upon encountering the cue (e.g., eating fruit instead of candy). Because selection of the cue increases its cognitive accessibility, it is easier to detect and respond to it in a reflexive manner that is immediate and efficient (Aarts, Dijksterhuis, \& Midden, 1999; Brandstätter, Lengfelder, \& Gollwitzer, 2001; Webb \& Sheeran, 2004; 2007). Thus, the mental link formed between the if and then components automatizes action control, which increases goal attainment across a variety of domains (for a meta-analysis, see Gollwitzer \& Sheeran, 2006).

Most relevant to our current research aim, implementation intentions have been shown to attenuate bias in the context of stereotypes. For example, in a study described by Gollwitzer and Schaal (1998), male participants received false feedback on a measure of stereotypicality to first activate an egalitarian motivation. Then, they were given the goal of judging women in a fair and nonstereotypi- 
cal manner on a subsequent Stroop-like test. Specifically, the task required them to quickly name the color of gender-typical and gender-neutral target words that followed a female name prime (INA or BEA) or a string of random letters (CCC). Some participants were randomly assigned to adopt an implementation intention specifying how to accomplish their goal (e.g., "If I see INA, then I will ignore her gender!"). Those in the goal condition took longer to correctly name the color of stereotypical words following the feminine primes, whereas those in the implementation intention group were able to name the gender-typical and gender-neutral attributes equally fast following the presentation of the "INA" prime. Thus, the strategy was effective in reducing stereotypical responses when the selected cue was encountered on the task.

Implementation intentions may also help override implicit forms of racial bias. Across a pair of studies using the weapons identification task, Stewart and Payne (2008) had participants quickly and correctly identify the appearance of a handgun or tool following a Black or White facial prime. Before starting the task, participants formed an implementation intention to think the word "safe" upon seeing a Black face to counteract negative racial stereotypes. These participants showed less racial bias in their categorization of the objects compared to participants who were instructed to think the task relevant words "quick" or "accurate" in response to the Black facial prime. Additionally, Mendoza, Gollwitzer, and Amodio (2010) found that implementation intentions could increase accuracy on a stereotyping measure in which participants had to quickly decide whether to shoot or not shoot Black and White targets holding guns or innocuous objects. Compared to those forming a simple goal, participants who used an if-then implementation intention strategy directing them to either ignore the race of the target (Study 1) or turn their attention to goal-relevant stimuli (Study 2) made fewer errors overall.

The aforementioned findings suggest that implementation intentions may serve as a viable strategy for initiating less biased responses. However, previously examined implementation intentions often instruct individuals to suppress their stereotypes or ignore social categories, and these strategies can backfire in intergroup settings (Plant, Devine, \& Peruche, 2010; Shih \& Young, 2016). Consequently, we investigate if implementation intentions lead to less biased evaluations when the if-then plan does not require ignoring or suppressing information. More specifically, we predict that individuals who are given a goal to be fair will provide more positive employee evaluations when they supplement it with a perspective taking implementation intention (Hypothesis 2).

\section{Current Research}

Based on the past research showing that perspective taking can, at times, lead to decreased stereotyping and that implementation intentions can help facilitate egalitarian goals, we examine whether perspective taking implementation intentions can serve as a viable strategy for reducing gender bias in the workplace. More specifically, we predict an interaction between the gender of the employee being evaluated and the strategy used, such that gender bias will be less pronounced in the implementation intention condition than the simple goal condition (Hypothesis 3 ). We also explore whether our strategy reduces broader gender-based attitudes, as suggested by past perspective taking literature (e.g., Galinsky \& Moskowitz, 2000). In our study, participants first provide a performance review of a nonstereotypical male or female employee working in a male-typed domain (i.e., consulting) and then complete a general sexism measure.

\section{METHOD}

\section{Design}

The study used a 2 (employee gender: male vs. female) x 2 (strategy: simple goal vs. simple goal with perspective taking implementation intention) between-subjects design.

\section{Participants}

The study was administered electronically via Qualtrics and posted on Amazon Mechanical Turk (MTurk), where a total of 205 participants completed it for $\$ 1.25$ of compensation. The sample (52\% male, $71 \%$ White) had an average work experience of 12.85 years $(S D=9.92)$ and approximately half (49\%) of the participants were $26-35$ years old.

\section{Manipulations}

Employee gender. Participants evaluated either a male (Brendan) or female (Brenda) employee who was undergoing a performance review at a consulting company. Information about gender was conveyed through the previously pretested name and pronouns used in a summary letter that highlighted the employee's accomplishments in the past year. The review was purposely ambiguous in terms of gender stereotypic behaviors and job performance, with the employee demonstrating some positive (e.g., demonstrates leadership; good problem solver) and negative (e.g., lacks follow through; misses deadlines) work aspects.

Strategy. Participants were provided with a cover story that the consulting company was interested in conducting the performance review in an unbiased manner. To best accomplish this, participants in the simple goal condition were instructed to adopt the following goal strategy, "I will evaluate the employee fairly!" By comparison, the implementation intention condition was given a strategy that read, "I will evaluate the employee fairly! And if I have concerns about the review, then I will put myself in the employee's shoes to better understand what might have happened." Thus, participants across the two strategy con- 
ditions were given the same fairness goal, with one group also being provided with a specific if-then plan on how to accomplish it, as in past implementation intention studies (Gollwitzer, 1993, 1999).

\section{Measures}

Since past research has shown that gender bias against working women can differentially emerge on perceived abilities, performance, and traits (e.g., Heilman et al., 2004; Rudman \& Glick, 1999, 2001), we measured these dimensions separately along with sexist attitudes.

Work skillset. Participants used a 5-point scale $(1=$ very poor, $5=$ very good $)$ to rate the employee on four skillsets: interpersonal skills, problem-solving skills, technical skills, and leadership skills. Responses were averaged on this dimension to create a work skillset index $(\alpha=.71)$, with higher scores reflecting more positive perceptions of the employee's abilities.

Work performance. Participants also rated the employee on a 5 -point scale $(1=$ very poor, $5=$ very good $)$ on six performance dimensions: work consistency, work quality, work dependability, work productivity, overall work potential, and overall work performance. A composite $(\alpha=$ .79) was created by averaging these items, such that higher scores indicated more favorable perceptions of the employee's work performance.

Work traits. Participants used a 5-point bipolar scale to rate the employee on eight work traits: passive-assertive, uncooperative-cooperative, apathetic-enthusiastic, incompetent-competent, logical-emotional (reversed), selfish-caring, uncreative-creative, and dependent-independent. Responses to these items were averaged to create a work traits index $(\alpha=.68)$, with higher scores indicating more positive trait qualities ascribed to the employee. Two additional neutral work traits (sad-happy and unlucky-lucky) were included as fillers on this measure.

Promotion recommendation. Participants were given a dichotomous option to choose "no" or "yes" to the statement, "I would recommend this employee for promotion."

Sexism. Participants used a 5-point scale (1 = strongly disagree, $5=$ strongly agree) to complete the Ambivalent Sexism Inventory, which is a 22 -item measure that taps into two separate dimensions of sexism (for full scale, see Glick \& Fiske, 1996). Hostile sexism scores $(\alpha=.94)$ were obtained by averaging responses across 11 items such as, "Women are too easily offended," and "Women seek to gain power by getting control over men." Benevolent sexism scores $(\alpha=.88)$, were obtained by averaging responses across 11 items such as, "Women should be cherished and protected by men," and "A good woman should be set on a pedestal by her man." High scores on both of these subscales reflect more sexist attitudes toward women.

Attention and Manipulation Checks. To ensure that participants properly processed our manipulations, we asked them to indicate the gender of the employee under review and to type their randomly assigned strategy into an open-ended response box after mentally rehearsing it three times. Furthermore, we used a 5-point scale $(1=$ not at all, 5 = very much) to measure the participants' motivation to follow through with their goal with a single item ("How motivated were you to evaluate the employee fairly?"), as well as their ability and willingness to engage in perspective taking with four items $(\alpha=.84$; "How motivated were you to put yourself in the shoes of the employee you were evaluating?"; "How easily were you able to take the perspective of the employee you evaluated?"; "How important was it for you to try and think about the standpoint of the employee you evaluated?"; "How able were you to understand the standpoint of the employee that you evaluated?").

\section{Procedure}

Following the electronic consent form, participants were provided with a cover story that they would be tasked with helping a consulting company conduct a performance review. Before completing the employee evaluation, they received a company overview on letterhead which provided them background on the fictitious American Management Consulting Group, including its work values and culture. Next, participants were given their randomly assigned (goal or implementation intention) strategy to use during the performance review. Then, they read a supervisor's written summary of the (male or female) employee's recent accomplishments. Finally, they provided their own evaluations of the employee on three different work-related dimensions (e.g., skillset, performance, and traits), as well as responded to the goal and perspective taking items, sexism scale, and basic demographic questions before being debriefed.

\section{RESULTS}

Based on previously conducted gender bias, perspective taking, and implementation intention research, we formed three hypotheses. First, we predicted a main effect of gender, such that male employees would receive more favorable evaluations than female employees (Hypothesis 1). Second, we predicted a main effect of goal strategy, such that the perspective taking implementation intention condition would lead to more positive employee evaluations compared to the simple goal condition (Hypothesis 2). Last, we expected these effects to be qualified by a significant interaction, such that gender bias would be less pronounced among participants using a perspective taking implementation intention (Hypothesis 3).

\section{Preliminary Analyses}

Data exclusion. Of the original 205 participants, 10 were excluded for not processing the strategy correctly, and 11 were removed for incorrectly reporting the gender of the 
employee. In addition, four other participants had outlying scores $(>3 S D)$ on the measures of work skillset $(n=1)$, performance $(n=1)$, traits $(n=1)$, and perspective taking $(n$ $=1)$. Analyses were therefore conducted on a total of 180 participants $\left(n_{\text {goal }}=96, n_{\text {implementation }}=84\right)$ with a similar demographic composition as the full sample (53\% male, $74 \%$ White, 46\% 26-35 years old). The sample size had sufficient power at .82 based on a post-hoc power analysis using GPower (Faul, Erdfelder, Buchner, \& Lang, 2009).

Goal motivation. To test whether participants across conditions adopted the overall goal to evaluate the employee fairly, we conducted a one-sample t-test comparing the sample's mean $(M=4.68, S D=.62)$ to the midpoint (3) of the scale. This test was significant, $t(179)=36.17, p<.001$, indicating that all participants were sufficiently motivated to adopt the fairness goal. The two strategy groups also did not differ in their fairness goal motivation, $t(178)=1.46, p$ $=.138$.

Perspective taking. We also examined whether our strategy manipulation had its intended effect on levels of perspective taking. As expected, results from an independent samples $t$-test revealed that participants using the implementation intention strategy $(M=4.39, S D=.66)$ engaged in more perspective taking with the employee than those using the simple goal strategy $(M=4.18, S D=.68)$, $t(178)=2.10, p=.037$.

\section{Employee Evaluations}

We conducted a MANOVA on our three work-related measures (skillset, performance, and traits) using the two fixed factors of employee gender and strategy. Results revealed a marginal main effect of strategy, $F(3,174)=2.42$, $p=.068$, but no main effect of gender or interaction, $F \mathrm{~s}<1$. Exploratory univariate ANOVAs indicated that participants using a perspective taking implementation intention strategy $(M=4.16, S D=.64)$ had more positive perceptions of the employee's skillset than those using a simple goal $(M$ $=3.96, S D=.63), F(1,176)=4.45, p=.036$. Additionally, those using the implementation intention strategy $(M=3.96$, $S D=.48$ ) rated the employee marginally more favorably on work traits than those in the simple goal condition $(M=3.82$, $S D=.47), F(1,176)=3.79, p=.053$. There was no effect of strategy on the work performance measure, and all employee gender effects and interactions were not significant across the variables, all $F \mathrm{~s}<1$.

\section{Promotion Recommendation}

A chi-square analysis demonstrated that neither the employee gender, $\chi^{2}(1, N=179)=1.90, p=0.17$, nor the strategy condition, $\chi^{2}(1, N=179)=1.35, p=0.25$, influenced promotion recommendations. For instance, $47 \%$ of participants recommended the female be promoted, and $53 \%$ of the participants recommended the male be promoted. Furthermore, female employees were just as likely to be recommended for promotion regardless of the strategy used, $\chi^{2}(1, N=90)=.31, p=0.58$, as were male employees, $\chi^{2}(1$, $N=89)=1.55, p=0.21$.

\section{Sexism}

Separate 2 (employee gender: male vs. female) x 2 (strategy: simple goal versus simple goal with perspective taking implementation intention) between-subjects ANOVAs were conducted for hostile and benevolent sexism scores. For hostile sexism, we observed a significant main effect of strategy, $F(1,176)=8.09, p<.01$, such that perspective taking implementation intention participants $(M=$ 2.23, $S D=.98$ ) showed lower levels of hostile sexism compared to the simple goal participants $(M=2.64, S D=.99)$. Importantly, this strategy effect remained significant after controlling for participant gender in a separate ANCOVA, $F(1,176)=8.09, p=.018$. There was no main effect of employee gender, $F(1,176)=1.24, p=.266$, nor interaction, $F(1,176)=1.70, p=.194$, on hostile sexism. Furthermore, there were no main effects nor interaction for benevolent sexism, all $F_{\mathrm{s}}<1$.

\section{DISCUSSION}

In an effort to reduce long-standing patterns of gender workplace discrimination, we investigated whether perspective taking implementation intentions could be used to produce fairer evaluations of female employees. We predicted that men would receive more favorable performance reviews than women (Hypothesis 1), and that use of a perspective taking implementation intention strategy would result in more positive evaluations than a simple goal strategy (Hypothesis 2). We also expected that these effects would be qualified by an interaction between the two variables, such that gender bias was expected to be attenuated by the implementation intention strategy (Hypothesis 3 ). Consistent with past work on perspective taking and implementation intentions, we found that the perspective taking implementation intention strategy resulted in more positive employee evaluations and less hostile sexism than a simple goal intention. However, gender bias did not emerge in either condition and therefore, we did not find a moderating effect of strategy. We discuss the implications of these findings in further detail below.

\section{Implications and Future Work}

Contrary to past psychological and organizational behavior literature, our study did not produce a pattern of gender bias. This may, in part, be attributed to all participants being given the goal to evaluate the employee fairly. Consequently, participants in the simple goal condition may have also privately formed their own strategy for how to best accomplish this in a manner that did not necessarily involve perspective taking but nonetheless helped them 
reduce potential bias. In addition, we purposely created a mixed employee performance review that indicated both positive and negative behaviors but avoided gender specific attributes. Thus, this may have suppressed the automatic activation of social stereotypes. Future research should investigate whether altering the personal descriptors in the review influence the expression of gender bias.

Although gender bias did not emerge on work performance measures in our study, we did observe a decrease in hostile sexism through our implementation intention strategy. This change in attitudes is consistent with prior work on perspective taking that has shown positive shifts in the evaluation of ambiguously stereotyped groups (e.g., Galinsky \& Ku, 2004; Galinsky \& Moskowitz, 2000). For instance, Madera, Neal, and Dawson (2011) found that a perspective taking training exercise produced more positive attitudes toward non-English speakers by increasing empathy. Additionally, recent findings suggest that perspective taking can also indirectly change perceptions of minority members by increasing personal attraction to and support for organizations that endorse diversity initiatives (Madera, 2018). In line with these studies, we believe that our approach represents another strategy that can be implemented in the workplace to engage perspective taking and increase favorability toward stigmatized others. Future studies could more directly test the mediating process by which perspective taking implementation intention strategies achieve their impact on employee judgments.

Rather than trying to change perceptions of a negatively stereotyped target group, we attempted to reduce bias through a goal pursuit strategy that was designed to broadly engage perspective taking. We purposely phrased the ifthen statement in a manner that would allow participants to apply it equally, regardless of the employee's gender. In this respect, our approach is different from past bias intervention studies that typically aim to change well-learned associations through experimental manipulations that simultaneously promote the positive aspects of one group and highlight the negative attributes of another (for reviews, see Amodio \& Mendoza, 2010; Blair, 2002). For example, Dasgupta and Greenwald (2001) altered racial bias by exposing participants to photos of admired Black and disliked White individuals. Similarly, Kawakami, Phills, Steele, and Dovidio (2007) trained participants to approach Black and avoid White faces through the movement of joysticks toward and away from the self. These strategies may therefore be more likely to reverse, rather than eliminate, bias. By demonstrating that our strategy could boost evaluations for everyone, we were able to show how perspective taking implementation intentions can facilitate goal-consistent responses, which in turn, decreases the overall likelihood of stereotypes influencing behavior (as in Mendoza et al., 2010). Furthermore, the observed benefits of using if-then plans compared to a simple goal strategy are comparable to those found by Avery, Richeson, Hebl, and Ambady (2009), who showed that providing White participants with behavioral scripts can reduce anxiety within interracial workplace interactions.

To our knowledge, the present study is the first to investigate perspective taking implementation intentions and the first to examine goal pursuit in organizational contexts. Future research will therefore need to address remaining questions, such as whether perspective taking implementation intentions can still be effective when the employee confirms negative group stereotypes (e.g., women who lack agentic traits or are employed in low-power positions; Skorinko \& Sinclair, 2013). Another factor that is worth investigating is how colorblind or multicultural approaches to implementation intentions influence bias reduction, as there is mixed evidence on the intergroup effects of these two different ideologies (Plant, Devine, \& Peruche, 2010; Plaut, Thomas, Hurd, \& Romano, 2018; Richeson \& Nussbaum, 2004; Shih \& Young, 2016). Also, it is unclear how competitive motivations (e.g., protecting high or token status) or situational factors (e.g., having time-pressure or being cognitively depleted) would influence their effects. Although implementation intentions are theorized to protect the individual from these potential distractions (Gollwitzer \& Sheeran, 2006), it will be important to test these assumptions more directly in challenging work environments. In addition, it would be interesting for future studies to investigate whether perspective taking implementation intentions can mitigate the negative impact that having few organizational resources might have during critical evaluation periods (raises, promotions, etc.). Last, it will be important to investigate how personality variables, such as commitment to egalitarian goals and natural empathic ability, moderate the power of implementation intentions in reducing workplace bias.

\section{Conclusion}

To address gender disparities, some organizations including consulting firms - have begun to investigate how their employee evaluation practices can be revised to be more inclusive (Elejalde-Ruiz, 2016). The current research provides preliminary evidence that utilizing implementation intentions to engage perspective taking can benefit organizations seeking to make fair decisions. Through the adoption of a specific if-then statement encouraging them to put themselves in the shoes of an employee, individuals were able to give more positive work ratings overall (regardless of the target's gender) and express less hostile attitudes toward women. Compared to extensive diversity trainings that can be negatively perceived by members of nonstigmatized groups, this provides a promising yet simple intervention that companies may incorporate to help reduce workplace gender bias and sexism. 


\section{REFERENCES}

Aarts, H., Dijksterhuis, A., \& Midden, C. (1999). To plan or not to plan? Goal achievement or interrupting the performance of mundane behaviors. European Journal of Social Psychology, 29, 971-979. DOI: https://doi.org/10.1002/(SICI)10990992(199912)29:8<971::AID-EJSP963>3.0.CO;2-A

Ames, D. R. (2004a). Inside the mind reader's tool kit: Projection and stereotyping in mental state inference. Journal of Personality and Social Psychology, 87, 340-353. DOI: 10.1037/0022-3514.87.3.340

Ames, D. R. (2004b). Strategies for social inference: A similarity contingency model of projection and stereotyping in attribute prevalence estimates. Journal of Personality and Social Psychology, 87, 573-585. DOI: http://dx.doi. org/10.1037/0022-3514.87.5.573

Amodio, D. M., \& Mendoza, S. A. (2010). Implicit intergroup bias: Cognitive, affective, and motivational underpinnings. In B. Gawronski and B. K. Payne (Eds.), Handbook of implicit social cognition (pp. 353-374). New York: Guilford. DOI: 10.1558/imre.v16i2.232

Avery, D. R., Richeson, J. A., Hebl, M. R., \& Ambady, N. (2009). It does not have to be uncomfortable. The role of behavioral scripts in Black-White interracial interactions. Journal of Applied Psychology, 94, 1382-1393. DOI: http://dx.doi. org/10.1037/a0016208

Bain \& Company (2018). Gender pay gap. Retrieved from https:// www.bain.com/about/gender-pay-gap/

Bellstrom, K. (February 8, 2016). Exclusive: Accenture is the first big consulting firm to publish race and gender stats. Fortune. Retrieved from: http://fortune.com/2016/02/08/exclusive-accenture-is-the-first-big-consulting-firm-to-publishrace-and-gender-stats/

Bhattacharyya, R. \& Sachin, D. (September 20, 2016). Gender diversity: Big consultants far from being fair. The Economic Times. Retrieved from https://economictimes.indiatimes. com/jobs/gender-diversity-big-consultants-far-from-being-fair/articleshow/54418223.cms

Biernat, M., \& Manis, M. (1994). Shifting standards and stereotype-based judgments. Journal of personality and social psychology, 66(1), 5.

Blair, I. V. (2002). The malleability of automatic stereotypes and prejudice. Personality and Social Psychology Review, 6, 242261. DOI: https://doi.org/10.1207/S15327957PSPR0603_8

Brandstaetter, V., Lengfelder, A., \& Gollwitzer, P. M. (2001). Implementation intentions and efficient action initiation. Journal of Personality and Social Psychology, 81, 946-960. DOI: http://dx.doi.org/10.1037/0022-3514.81.5.946

Caruso, E. M., Epley, N., \& Bazerman, M. H. (2006). The costs and benefits of undoing egocentric responsibility assessments in groups. Journal of Personality and Social Psychology, 91, 857-871. DOI: http://dx.doi.org/10.1037/0022-3514.91.5.857

Catalyst. (June 21, 2017). Quick take: Women's earnings and income. Retrieved from http://www.catalyst.org/knowledge/ womens-earnings-and-income

Catalyst. (March 28, 2018). Quick take: Women in the workforce: United States. Retrieved from http://www.catalyst.org/ knowledge/women-workforce-united-states\#footnote9_ dziix3m
Dasgupta, N., \& Greenwald, A. G. (2001). On the malleability of automatic attitudes: Combating automatic prejudice with images of admired and disliked individuals. Journal of Personality and Social Psychology, 81, 801-814. DOI: 10.1037//0022-3514 81.5.800

Davis, M., Conklin, L., Smith, A., \& Luce, C. (1996). Effect of perspective-taking on the cognitive representation of persons: a merging of self and other. Journal of Personality and Social Psychology, 70, 713-726. DOI: http://dx.doi. org/10.1037/0022-3514.70.4.713

Eagly, A. H. (1987). Sex difference in social behavior: A social-role interpretation. Hillsdale, NJ: Lawrence Erlbaum Associates, Inc. DOI:https://doi.org/10.4324/9780203781906

Eagly, A. H., \& Karau, S. J. (2002). Role congruity theory of prejudice toward female leaders. Psychological Review, 109, 573598. DOI: 10.1037//0033-295X.109.3.573

Eagly, A. H., \& Wood, W. (1991). Explaining sex differences in social behavior: A meta-analytic perspective. Personality and Social Psychology Bulletin, 17, 306-315. DOI: https://doi. org/10.1177/0146167291173011

Elejalde-Ruiz, A. (September 9, 2016). To retain women, consulting firm targets gender communication differences. Chicago Tribune. Retrieved from https://www.chicagotribune. com/business/ct-bcg-women-communication-0906-biz20160906-story.html

Epley, N., Keysar, B., van Boven, L., \& Gilovich, T. (2004). Perspective taking as egocentric anchoring and adjustment. Journal of Personality and Social Psychology, 87, 327-339. DOI: 10.1037/0022-3514.87.3.327

Faul, F., Erdfelder, E., Buchner, A., \& Lang, A.-G. (2009). Statistical power analyses using G*Power 3.1: Tests for correlation and regression analyses. Behavior Research Methods, 41, 11491160. DOI: 10.3758/BRM.41.4.1149

Fiske, S. T., Cuddy, A. J. C., Glick, P., \& Xu, J. (2002). A model of (often mixed) stereotype content: Competence and warmth respectively follow from perceived status and competition. Journal of Personality and Social Psychology, 82, 878-902. DOI: $10.1037 / / 0022-3514.82 .6 .878$

Foschi, M. (1996). Double standards in the evaluation of men and women. Social Psychology Quarterly, 59, 237-254. DOI: http://dx.doi.org/10.2307/2787021

Frantz, C. M., \& Janoff-Bulman, R. (2000). Considering both sides: The limits of perspective-taking. Basic and Applied Social Psychology, 22, 31-42. DOI: https://doi.org/10.1207/ S15324834BASP2201_4

Galinsky, A. D., \& Ku, G. (2004). The effects of perspective-taking on prejudice: The moderating role of self-evaluation. Personality \& Social Psychology Bulletin, 30, 594-604. DOI: https://doi.org/10.1177/0146167203262802

Galinsky, A. D., \& Moskowitz, G. B. (2000). Perspective-taking: Decreasing stereotype expression, stereotype accessibility, and in-group favoritism. Journal of Personality \& Social Psychology, 78, 708-724. DOI: http://dx.doi.org/10.1037/00223514.78.4.708

Glick, P., \& Fiske, S. T. (1996). Ambivalent Sexism Inventory.[Database record]. Retrieved from PsychTESTS.

Gollwitzer, P. M. (1993). Goal achievement: The role of intentions. European Review of Social Psychology, 4, 141-185. DOI: https://doi.org/10.1080/14792779343000059 
Gollwitzer, P. M. (1999). Implementation intentions: Strong effects of simple plans. American Psychologist, 54, 493-503. DOI: http://dx.doi.org/10.1037/0003-066X.54.7.493

Gollwitzer, P. M., \& Schaal, B. (1998). Meta-cognition in action: The importance of implementation intentions. Personality and Social Psychology Review, 2, 124-136. DOI: https://doi. org/10.1207/s15327957pspr0202_5

Gollwitzer, P. M., \& Sheeran, P. (2006). Implementation intentions and goal achievement: A meta-analysis of effects and processes. In. M. P. Zanna (Ed.), Advances in experimental social psychology (pp. 69-119). San Diego, CA: Academic Press. DOI: https://doi.org/10.1016/S0065-2601(06)38002-1

Heilman, M. E. (2012). Gender stereotypes and workplace bias. Research in Organizational Behavior, 32, 113-135. DOI: http://dx.doi.org/10.1016/j.riob.2012.11.003

Heilman, M. E., \& Okimoto, T. G. (2007). Why are women penalized for success at male tasks? The implied communality deficit. Journal of Applied Psychology, 92, 81-92. DOI: 10.1037/0021-9010.92.1.81

Heilman, M. E., Wallen, A. S., Fuchs, D., \& Tamkins, M. M. (2004). Penalties for success: Reactions to women who succeed at male gender-typed tasks. Journal of Applied Psychology, 89, 416-427. DOI: http://dx.doi.org/10.1037/0021-9010.89.3.416

Kawakami, K., Phills, C., Steele, J. R., \& Dovidio, J. F. (2007). (Close) distance makes the heart grow fonder: Improving implicit racial attitudes and interracial interactions through approach behaviors. Journal of Personality and Social Psychology, 92, 957-971. DOI: http://dx.doi.org/10.1037/00223514.92.6.957

Koch, A. J., D'Mello, S. D., \& Sackett, P. R. (2015). A meta-analysis of gender stereotypes and bias in experimental simulations of employment decision making. Journal of Applied Psychology, 100, 128-161. DOI: 10.1037/a0036734

Laurent, S. M., \& Meyers, M. W. (2011). I know you're me, but who am I? Perspective taking and seeing the other in the self. Journal of Experimental Social Psychology, 47, 1316-1319. DOI: http://dx.doi.org/10.1016/j.jesp.2011.05.018

Madera, J. (2018). Situational perspective taking as an intervention for improving attitudes toward organizations that invest in diversity management programs. Journal of Business Psychology, 33, 423-442. DOI: https://doi.org/10.1007/ s10869-017-9502-0

Madera, J., Neal, J. A., \& Dawson, M. (2011). A strategy for diversity training: Focusing on empathy in the workplace. Journal of Hospitality \& Tourism Research, 35, 469-487. DOI: https:// doi.org/10.1177/1096348010382240

McKinsey \& Company (2016). Women Matter 2016: Reinventing the workplace to unlock the potential of gender diversity. Retrieved from https://www.mckinsey.com/ /media/ mckinsey/featured\%20insights/women\%20matter/reinventing $\% 20$ the $\% 20$ workplace $\% 20$ for $\% 20$ greater $\% 20$ gender\%20diversity/women-matter-2016-reinventing-the-workplace-to-unlock-the-potential-of-gender-diversity.ashx

McKinsey \& Company (2018). Women in the workplace 2018. Retrieved from https://womenintheworkplace.com

Mendoza, S. A., Gollwitzer, P. M., \& Amodio, D. M. (2010). Reducing the expression of implicit stereotypes: Reflexive control through implementation intentions. Person- ality and Social Psychology Bulletin, 36, 512-523. DOI: $10.1177 / 0146167210362789$

Myers, M. W., \& Hodges, S. D. (2012). The structure of self-other overlap and its relationship to perspective taking. Personal Relationships, 19, 663-679. DOI: http://dx.doi.org/10.1111/ j.1475-6811.2011.01382.x

Plant, A. E., Devine, P. G., \& Peruche, M. B. (2010). Routes to positive interracial interactions: Approaching egalitarianism or avoiding prejudice. Personality and Social Psychology Bulletin, 36, 1135-1147. DOI: 10.1177/0146167210378018

Plaut, V. C., Thomas, K. M., Hurd, K., \& Romano, C. A. (2018). Do color blindness and multiculturalism remedy or foster discrimination and racism? Current Directions in Psychological Science, 27, 200-206. DOI: https://doi. org/10.1177/0963721418766068

Richeson, J. A., \& Nussbaum, R. J. (2004). The impact of multiculturalism versus color-blindness on racial bias. Journal of Experimental Social Psychology, 40, 417-423. DOI: 10.1016/ j.jesp.2003.09.002

Rudman, L. A., \& Glick, P. (1999). Feminized management and backlash toward agentic women: The hidden costs to women of a kinder, gentler image of middle-managers. Journal of Personality and Social Psychology, 77, 1004-1010. DOI: 10.1037/0022-3514.77.5.1004

Rudman, L. A., \& Glick, P. (2001). Prescriptive gender stereotypes and backlash toward agentic women. Journal of Social Issues, 57, 743-762. DOI: http://dx.doi.org/10.1111/00224537.00239

Shih, M., \& Young, M. J. (2016). Identity management strategies in workplaces with color-blind diversity policies. In H. A. Neville, M. E. Gallardo, \& D. W. Sue (Eds.), The myth of racial color blindness: Manifestations, dynamics, and impact (pp. 261-274). Washington, DC: American Psychological Association. DOI: http://dx.doi.org/10.1037/14754-016

Skorinko, J. L., \& Sinclair, S. A. (2013). Perspective taking can increase stereotyping: The role of apparent stereotype confirmation. Journal of Experimental Social Psychology, 49, 1018. DOI: http://dx.doi.org/10.1016/j.jesp.2012.07.009

Stewart, B. D., \& Payne, B. K. (2008). Bringing automatic stereotyping under control: Implementation intentions as efficient means of thought control. Personality and Social Psychology Bulletin, 34, 1332-1345. DOI: 10.1177/0146167208321269

Tarrant, M., Calitri, R., \& Weston, D. (2012). Social identification structures the effects of perspective taking. Psychological Science, 23, 973-978. DOI: https://doi. org/10.1177/0956797612441221

Tomenendal, M. \& Boyoglu, C. (2014). Gender imbalance in management consulting firms-a story about the construction and effects of organizational identity. Management and Organizational Studies, 1, 30-43. DOI: https://doi.org/10.5430/ mos.v1n 2 p30

Valian, V. (2000). Why so slow? The advancement of women. Cambridge, MA: MIT Press. DOI: 10.2307/2653855

Vescio, T., Sechrist, G., \& Paolucci, M. (2003). Perspective-taking and prejudice reduction: The mediational role of empathy arousal and situational attributions. European Journal of Social Psychology, 33, 455-472. DOI: https://doi.org/10.1002/ ejsp.163

Webb, T. L., \& Sheeran, P. (2004). Identifying good opportunities 
to act: Implementation intentions and cue discrimination. European Journal of Social Psychology, 34, 407-419. DOI: http:// dx.doi.org/10.1002/ejsp.205

Webb, T. L., \& Sheeran, P. (2007). How do implementation intentions promote goal attainment? A test of component processes. Journal of Experimental Social Psychology, 43, 295-302. DOI: 10.1016/j.jesp.2006.02.001

RECEIVED 05/14/18 ACCEPTED 02/07/19 